\title{
ESTUDO EMPIRICO DA PERCEPÇÃO DOS ACADÊMICOS DO CURSO DE CIÊNCIAS CONTÁBEIS QUANTO ÀS LICITAÇÕES PÚBLICAS E TRANSPARÊNCIA
}

\author{
Sandra Maria de Faria ${ }^{1}$ \\ Magno Alves Ribeiro ${ }^{2}$ \\ Eder Eugenio Munhão ${ }^{3}$
}

\section{RESUMO}

Este artigo tem como finalidade, analisar a percepção dos acadêmicos iniciantes e concluintes do curso de Ciências Contábeis da Universidade do Estado de Mato Grosso (UNEMAT) Campus de Tangará da Serra - MT, quanto ao tema licitações públicas e transparência. Para que o estudo atingisse tal objetivo foram utilizados procedimentos metodológicos dentre os quais citam-se revisão bibliográficas. O estudo empírico se deu através da buscar de dados pela aplicação de questionários. Os resultados em geral mostram que os acadêmicos acreditam que a falta de transparência prejudica o controle feito pela sociedade, possuem desconfiança em relação às informações divulgadas de processos licitatórios, além do mais não participam dos mesmos, a pesquisa também mostrou que o motivo dessa não participação, é a falta de interesse do próprio acadêmico. Deste modo, verificou-se que há necessidade de estratégias para que haja maior comprometimento de todos os acadêmicos no processo de fiscalizar desde a motivação até o controle social efetivo sobre os gastos público.

Palavras-chave: Administração Pública. Licitações. Transparência.

\section{INTRODUÇÃO}

É importante para a Administração Pública e para toda a sociedade que ressalte o papel das Licitações para o equilíbrio e a transparência nos gastos públicos. Sendo essa obrigação imposta a todos os administradores públicos, os quais atuam em nome dos cidadãos, devendo zelar pela máquina pública.

Segundo Gomes Filho (2010), a Administração Pública deveria ter conhecimento das opiniões e percepções da população em relação ao governo e ao planejamento adotado, de forma a atingir a satisfação das necessidades atuais da sociedade e garantir a confiança e legitimidade do governo.

Para Mendes (2010), as compras de bens e serviços públicos, quando feitas de forma correta, diminuindo custos e evitando dispêndios monetários desnecessários, trazem diversos benefícios para todos, como a melhoria da saúde pública, maior segurança, e melhor

\footnotetext{
${ }^{1}$ Acadêmica do curso de Ciências Contábeis da UNEMAT - Campus de Tangará da Serra, e-mail: Sandra.faria@unemat.br.

${ }^{2}$ Mestre em Administracion Y Finanzas pela Universidade de Extremadura (2003), Professor do curso de Ciências Contábeis da UNEMAT - Campus de Tangará da Serra, e-mail: magnoalves@ unemat.br.

${ }^{3}$ Mestrando em Ciências Contábeis do Minter UNISINOS/UNEMAT, e-mail: edermunhao@unemat.br 
educação. Logo, o conhecimento a respeito das percepções daqueles interessados sobre a forma de atuação da administração pública é importante, pois serve como ferramenta para tomar medidas necessárias para prevenção e detecção de fraudes encontradas hoje na Administração Pública (MENDES, 2010).

O presente estudo se faz relevante, pois nesta conjuntura de transformações do modo de agir de todos os poderes da União, dos Estados, do Distrito Federal e dos Municípios, com níveis elevados de diversas denúncias pelo mau uso da máquina Pública Administrativa, em especial nas contratações decorrentes de procedimentos licitatórios fraudulentos.

Exemplo disso são os acontecimentos divulgados pela mídia, mais precisamente a matéria que foi apresentada no dia 18/03/2012 (domingo) pelo Fantástico, a reportagem mostrava como funcionava um esquema para fraudar licitações da saúde pública, feito entre empresas fornecedoras e agentes públicos criminosos (G1, 2012).

Outro fato que não se deve esquecer é a Operação Hygea desencadeada em $2010 \mathrm{em}$ quatro Estados, incluindo a cidade de Tangará da Serra. A Controladoria Geral da União CGU em cooperação com a Polícia Federal elaborou uma operação para desarticular um esquema de desvios e fraudes em licitações e contratos do Governo Federal (CGU, 2010). Estes e muitos outros escândalos permitem que o dinheiro público escoe pelos esgotos da corrupção, isso afeta diretamente os cidadãos e a transparência na Administração Pública.

Sendo assim, tem como objetivo geral analisar a percepção dos acadêmicos do curso de Ciências Contábeis acerca licitações públicas e transparência nos processos licitatórios realizados pela Administração Pública. Especificamente procurou-se: 1) Descrever os conceitos e entendimento sobre a Lei 8.666/1993 e a transparência pública no contexto brasileiro; 2) Verificar a influência do ensino da Universidade do Estado de Mato Grosso na formação desses novos profissionais.

Tendo em vista que a Universidade se propõe a formar profissionais capacitados e qualificados ao exercício profissional com visão crítica, inovadores, com postura ética frente às organizações, tanto pública como privada. Logo torna-se importante conhecer a opinião dos futuros contadores, possíveis líderes de mercado, a respeito do referido tema.

Nessa linha de pensamento, pretende-se com o presente artigo responder ao seguinte questionamento: Qual o nível de percepção dos acadêmicos do curso de Ciências Contábeis sobre o tema licitações e transparência pública? 


\section{REFERENCIAL TEÓRICO}

\subsection{Administração Pública}

A Administração Pública pode ser entendida como uma organização, e os lideres são todos aqueles que atuam em nome da sociedade, sua atividade é subordinada de forma legal onde assegura a implementação das normas necessárias para satisfação das necessidades coletivas públicas.

Andrade (2002) conceitua Administração como, sendo conceitos advindos do Direito Administrativo, todo procedimento preordenado à realização de seus serviços que visa à satisfação das necessidades coletivas.

Segundo Meirelles (1990), “Administração Pública, portanto é a gestão de bens e interesses qualificados da comunidade no âmbito Federal, Estadual, ou Municipal, visando o bem comum".

Na concepção dos autores o principal objetivo da Administração Pública é o interesse coletivo onde o administrador público e seus agentes executam a função administrativa do Estado obedecendo aos princípios constitucionais da Legalidade, Impessoalidade, Moralidade, Publicidade e Eficiência.

Para Meirelles (1990), “A estrutura administrativa compreende a sua estrutura e suas atividades sobre o qual repousa toda a concepção moderna de organização e funcionamento dos serviços públicos". Nesse contexto, entender como funciona a estrutura organizacional da Administração Pública é papel de toda sociedade, somente assim poderá fiscalizar os recursos públicos evitando-se desvios de finalidade por parte dos gestores públicos.

Nas palavras de Meirelles (1990), na Administração Pública não há liberdade nem vontade pessoal. Enquanto na administração particular é lícito fazer tudo que a lei não proíbe, na Administração Pública só é permitido fazer o que a lei autoriza. Portanto a Administração Pública não possui liberdade quando deseja contratar, pois deve respeitar todos os requisitos exigidos pela lei visando o interesse público.

\subsection{Licitações Públicas}

Para melhor entendimento do assunto, será apresentado o conceito de licitação segundo a Lei ${ }^{\circ}$ 8.666/93, (Lei de Licitações e Contratos Administrativos) de 21 de julho de 1993. A referida lei é um processo de crescente legalização voltado, de um lado, a ampliação do dever de licitar e do outro, o administrador público para decidir a melhor forma de licitar. 
No entendimento do Tribunal de Contas da União - TCU (2003, p.15):

Licitação é o procedimento administrativo formal em que a Administração Pública convoca, mediante condições estabelecidas em próprio (edital ou convite), empresas interessadas na apresentação de propostas para o oferecimento de bens e serviços.

Já para Davi (2012, p.20):

A licitação deve ser proposta com a finalidade de conseguir auferir um custobenefício privilegiado para o Poder Público. Quer dizer, toda compra, obra, serviço que a Administração Pública realizar por meio de licitação deverá ser uma experiência vantajosa para o Estado. Notadamente, as licitações devem ser pautadas pela ética e pela transparência.

Os dois conceitos apresentam traços semelhantes, demonstrando ambas diversas características e mecanismo legal no qual às entidades governamentais, tanto diretas como indiretas, devem promover para proporcionar disputa entre os interessados em celebrar negócios com a administraçãopública devidamente instituída pela Lei no 8.666/1993 que veio a regulamentar o art. $37 \S$ XXI da Constituição Federal. A lei supracitada relata que "Ressalvados os casos específicos na legislação, às obras, serviços, compras e alienações serão contratados mediante processo de licitação pública que assegure igualdade de condição a todos os concorrentes" (BRASIL, 2002).

De acordo com o artigo 37 da Constituição Federal, o processamento e julgamento da licitação constituirão princípios básicos que norteiam os procedimentos licitatórios, conforme descritos no Quadro 1.

Quadro 1. Princípios de Licitações

\begin{tabular}{|l|l|}
\hline \multicolumn{1}{|c|}{ PRINCÍPIOS } & \multicolumn{1}{c|}{ DESCRIÇÃO } \\
\hline Princípio da Legalidade & $\begin{array}{l}\text { Vincula os licitantes e a Administração Pública às regras estabelecidas as } \\
\text { normas e princípios em vigor. }\end{array}$ \\
\hline Princípio da Isonomia & $\begin{array}{l}\text { Significa dar tratamento igual a todos os interessados. É condição essencial } \\
\text { para garantir a competição em todas as fases da licitação. }\end{array}$ \\
\hline Princípio da Impessoalidade & $\begin{array}{l}\text { Garantir que o processo busque a melhor alternativa, sem vícios que } \\
\text { restrinjam a participação ou sem atributos que direcionam a seleção. }\end{array}$ \\
\hline $\begin{array}{l}\text { Princípio da Moralidade e da } \\
\text { Probidade Administrativa }\end{array}$ & $\begin{array}{l}\text { A conduta dos licitantes e dos agentes públicos deverá ser além de lícita, } \\
\text { compatível com a moral, a ética, os bons costumes e as regras da boa } \\
\text { administração. }\end{array}$ \\
\hline Princípio da Publicidade & $\begin{array}{l}\text { Qualquer interessado deve ter acesso às licitações públicas e seu controle, } \\
\text { mediante divulgação dos atos praticados pelos administradores em todas as } \\
\text { fases da licitação. }\end{array}$ \\
\hline $\begin{array}{l}\text { Princípio da Vinculação ao } \\
\text { Instrumento Convocatório }\end{array}$ & $\begin{array}{l}\text { Obriga a administração e o licitante a observarem as normas e condições } \\
\text { estabelecidas no ato convocatório. Nada poderá ser criado ou feito sem que } \\
\text { haja previsão no ato convocatório. }\end{array}$ \\
\hline $\begin{array}{l}\text { Princípio do Julgamento } \\
\text { Objetivo }\end{array}$ & $\begin{array}{l}\text { Esse princípio significa que o administrador deve observar critérios objetivos } \\
\text { definidos no ato convocatório para o julgamento das propostas. Afasta a } \\
\text { possibilidade de o julgador utilizar-se de fatores subjetivos ou de critérios não } \\
\text { previstos no ato convocatório, mesmo que em benefício da própria } \\
\text { Administração. }\end{array}$ \\
\hline
\end{tabular}

Fonte: (adaptado da Constituição Federal, 2002, IN Lei 8.666/93, Art.3º). 
Segundo a Lei 8.666/93 em seu Art. nº 22 estabelecem cinco modalidades de licitação sendo: Concorrência, Tomada de Preços, Convite, Concurso, Leilão e o pregão a sexta modalidade criada posteriormente pela Lei $\mathrm{n}^{\circ}$ 10.520/02, mas, também subsidiada pela Lei 8.666/93 (BRASIL, 2002).

Cada modalidade de licitação tem suas próprias características, no qual são destinadas a determinados tipos de contratação.

\subsubsection{Concorrência Pública}

É a modalidade da qual podem participar quaisquer interessados que, nas fases de habilitação preliminar comprovem possuir os requisitos mínimos de qualificação exigidos no edital para execução do objeto da licitação (TCU, 2003).

Em conformidade com os artigos 21, 22 e 23 da Lei 8.666/93, esta modalidade é realizada com ampla publicidade visando assegurar a participação de quaisquer interessados que preencham os requisitos estabelecidosno edital convocatório, configura-se espécie para contrato de grande valor não sendo exigido o registro prévio de cadastro dos interessados, basta que os mesmos cumpram as condições estabelecidas no edital. O edital deverá ser publicado com no mínimo trinta dias de intervalo entre a publicação e os recebimentos das propostas de menor preço exceto quanto adotado um certame de acordo com os tipos: menor preço e melhor técnica, este prazo será de quarenta e cinco dias.

O montante para haver esse tipo de licitação deve ser acima de $\mathrm{R} \$ 1.500 .000,00$ para obras de serviços e engenharia e o montante superior a $650.000,00$ para realização de compras e serviços.

\subsubsection{Tomada de Preços}

Essa modalidade é realizada entre interessados devidamente cadastrados ou que atenderem a todas as condições exigidas para cadastramento até o terceiro dia anterior a data do recebimento das propostas, observada a necessária qualificação (TCU, 2003).

Segundo a Lei 8.666/93 em seus artigos 21 e 23, esta modalidade de licitação exige-se dos interessados que estejam devidamente cadastrados ou que preencham os requisitos para cadastro até o terceiro dia anterior a data do recebimento das propostas observada as qualificações (art.22inciso2 ${ }^{\circ}$ Lei 8.666/93). 
O montante para haver esse tipo de licitação deve estar entre $R \$ 150.000,00$ e $R \$$ 1.500.000,00 para obras ou serviços de engenharia e montante entre $\mathrm{R} \$ 80.000,00$ e $\mathrm{R} \$ 650.000,00$ para outras compras e serviços, estes valores estão dentro dos limites estabelecidos em Lei.

O grande diferencial desta modalidade com a Concorrência refere-se à existência de habilitação prévia dos licitantes, através de registros cadastrais, (os cadastros são os registros dos fornecedores de bens, executores de obras e serviços junto ao órgão da entidade administrativa que realizam licitações).

O prazo desta modalidade é de quinze dias, no mínimo entre a publicação e a data fixada para o recebimento da proposta, porém se o certame for julgado na conformidade "tipos", através dos critérios, "melhor técnica" ou "Técnica e preço" o prazo se estenderá para 30 dias.

\subsubsection{Convite}

O convite é a modalidade de licitação entre interessados do ramo pertinente ao seu objeto. A administração escolhe quem quer convidar, entre os possíveis interessados, cadastrados ou não no órgão ou entidade licitadora (TCU, 2003).

Os artigos 21, 22 e 23 da Lei 8.666/93, caracterizam o convite como a modalidade de licitação em que a lei não exige publicação de edital.Visto que a convocação é feita por escrito através de carta convite de no mínimo três empresas pertinentes ao ramo do objeto licitado, podendo as empresas convidadas estar ou não cadastradas junto ao órgão ou entidade licitadora.Entretanto é permitida a participação de outras empresas que não tenham sido convidadas desde que estejam cadastradas junto ao órgão ou entidade licitadora e que manifestando tal interesse com vinte e quatro horas de antecedência da apresentação das propostas.

O valor do montante para ocorrer esse tipo de licitação deve ser de $\mathrm{R} \$ 15.000,00$ a $\mathrm{R} \$$ $150.000,00$ para obras ou serviços de engenharia ou valor entre $\mathrm{R} \$ 8.000,00$ e $\mathrm{R} \$ 80.000,00$ para outras compras e serviços. 


\subsubsection{Concurso}

$\mathrm{Na}$ lei 8.666/93 art. 22 inciso $4^{\circ}$ estabelece que "é a modalidade de licitação entre quaisquer interessados para escolha de trabalho técnico, científico ou artístico, mediante a instituição de prêmios ou remuneração aos vencedores" (BRASIL, 1993).

O TCU (2003) complementa que no concursoa premiação final funciona como fato de incentivo aos possíveis interessados em participar do concurso, podendo ser constituído de bem economicamente avaliável ou uma honraria de outra natureza, sendo que a esta modalidade deve haver ampla divulgação com antecedência mínima de quarenta e cinco dias, podendo ser prorrogado se houver necessidade.

\subsubsection{Leilão}

Em conformidade com a Lei 8.666/93 Art. $22 \S 5^{\circ}$ o leilão é a modalidade de licitação entre quaisquer interessados para a venda de bens móveis inservíveis a Administração ou de produtos legalmente apreendidos ou penhorados, ou para a alienação de bens imóveis, a quem oferecer o maior lance igual ou superior ao valor de avaliação (BRASIL, 1993).

O leilão tem característica própria, visto que o vencedor não sabe o valor que os diversos comprados atribuem ao objeto a ser vendido, embora tanto o vencedor quanto o comprador saibam os seus propósitos, baseados no valor ou estimativa para o objeto leiloado.

\subsubsection{Pregão Eletrônico e Presencial}

Pregão começou a ser utilizada pela Administração Pública Federal no ano de 2002 através da Lei $\mathrm{n}^{\circ} 10.520$, de 17 de julho de 2002 e foi estendida as demais esferas de Governo, tanto Estadual como Municipal.

O TCU (2003, p.25) conceitua pregão como:

Modalidade de licitação em que a disputa pelo fornecimento de bens e serviços comuns é feita em sessão pública. Os licitantes apresentam suas propostas de preço por escrito e por lances verbais, independente do valor estimado da contratação.

Segundo o TCU (2003) “O pregão é a modalidade alternativa ao Convite, Tomada de Preços e Concorrência”. Logo a Administração Pública não está obrigada a realizar o pregão toda vez que deseje obter um bem ou serviço de interesse comum, exceto nos casos de repasse de recursos públicos da União, conforme especificado no Decreto $n^{\circ}$ 5.504/2005. 
O pregão é exclusivamente do tipo menor preço, para aquisição de bens e contratação de serviços comuns. Na modalidade Pregão não são estipuladosvalores, poderá ser utilizada para qualquer valor estimando-se apenas na aquisição de bens e contratação de serviços comuns em conformidade com o artigo $1^{\mathrm{o}}$ do Decreto Federal 3.555/2000.

Para Santana (2008, p.33):

Pregão é a modalidade de licitação que se realiza presencial ou eletronicamente, no qual há disputa para oferecer à Administração Pública o melhor preço entre os licitantes, verbalmente ou não, visando à contratação de bens e serviços comuns.

Em geral, a disputa de novos valores é através de lances sucessivos por meio de Pregão eletrônico ou por lances verbas quando a administração optar pelo pregão presencial, até que se obtenham novos valores da melhor e mais vantajosa proposta para Administração Pública.

Embora o pregão possua características próprias que efetivem sua praticidade, as etapas dos seus procedimentos são semelhantes às modalidades previstas na Lei 8.666/93. Assim sendo, como os demais procedimentos, conforme lei 10.520/02 sua divisão é composta por:

- Fase interna ou preparatória - prevista art. $3^{\circ}$ da referida Lei,e nos artigos $8^{\circ}$ ao $10^{\circ}$ do Decreto Federal 3.555/2000, nesta fase ocorre os atos que vão desde a motivação da compra até a subscrição do documento convocatório. Durante esta fase os trabalhos são realizados em âmbito interno, com a participação do dirigente responsável por compras e contratações, da unidade administrativa ou área da qual se origine a demanda pela licitação.

- Fase externa - prevista no art. $4^{\circ}$ da Lei 10.520/2000 vai desde a publicação do edital e do aviso até a execução do objeto, sendo que nesta fase ocorre à participação direta dos interessados (BRASIL, 2002).

As publicações devem obedecer às regras estipuladas no art. 11 do Decreto Federal 3.555/2000, os quais determinam os casos que devem ser divulgados no Diário Oficial e jornal de grande circulação onde tenha lugar o certame, bem como haja necessidade de divulgação nacional e no "site" de cada órgão ou entidade do Poder Executivo.

Na modalidade pregão a participação é aberta a todos os interessados que atendam as exigências do edital de convocação, no qual se exige ampla publicidade conforme artigo 11 do Decreto Federal 3.555/2000, quanto à fase externa ocorre inversão de papéis primeiro 
avalia-se a habilitação apenas dos vencedores, portanto, daqueles ofertantes que apresentaram melhor proposta para a Administração Pública.

Como benefícios o pregão tem a simplicidade do procedimento e a adoção do pregão facilitar a participaçãode eventuais interessados, pela simplicidade, pela celeridade do procedimento e pela maior transparência do procedimento (TOLOSA FILHO, 2005).

Tanto a legislação quanto o TCU determinam que no edital de convocação a administração faça constar os critérios e objetivos, pelos quais julgará as propostas dos licitantes, devendo estes ser coerentes com os tipos de licitação que aquela Lei prevê, a saber: menor preço, melhor técnica, técnica e preço, e maior lance ou oferta.

O Tribunal de Contas da União (2003) definem os tipos de licitação da seguinte forma: menor preço, melhor técnica, técnica e preço e maior lance ou oferta.

O tipo menor preço é o mais usual de licitação, e é caracterizado pelo critério de que será considerada a proposta mais vantajosa que dentro das especificações estabelecidos no instrumento convocatório, apresente o menor preço (TCU, 2003).

O tipo melhor técnica será utilizado exclusivamente para contratação de serviços de natureza predominante intelectual, em especial elaboração de projetos, cálculos, fiscalização, supervisão e gerenciamento e de engenharia consultiva em geral e, em particular, para a elaboração de estudos técnicos preliminares e projetos básicos e executivos (TCU, 2003).

Quanto ao tipo técnica e preço, as propostas serão avaliadas segundo os critérios já citados, de capacitação e experiência do proponente, no fato de que a avaliação levará em conta a proposta técnica e a de preço, sendo atribuídos pesos a cada uma delas, efetuando-se a média ponderada, para a escolha da proposta mais vantajosa (TCU, 2003).

O maior lance ou ofertaé utilizado para alienações de bens ou concessão de direito real de uso. O vencedor será o licitante que apresentar a proposta ou lance com maior preço, dentre os licitantes qualificados. A qualificação se dará pela ordem decrescente dos prepôs propostos (TCU, 2003).

\subsection{Transparência Pública}

Através da transparência pública, os atos de desvio dos recursos públicos podem ser coibidos, para isso é necessário à prática de fiscalização por parte do cidadão.

Vê-se no princípio constitucional da publicidade elemento básico para o conceito de transparência pública, pois, não existem atos sigilosos quando se trata de compras de bens e serviços da administração pública, nos termos da Lei 8.666/93. 
No que tange o assunto, a transparência pública tem como carro chefe a Lei Complementar $n^{\circ}$ 101/2000 Lei de Responsabilidade Fiscal - LRF, a redação da referida lei em seu art. 48 e 49 estabelecem regras de transparência, que determinam que seja dada ampla divulgação aos instrumentos de gestão fiscal, através de meios eletrônicos de acesso público. Também determina incentivar a participação popular no processo orçamentário, acompanhando em tempo real a execução orçamentaria e adoção de sistema integrado da administração financeira e controle (BRASIL, 2000).

Ainda segundo art. 49 da LRF que dispõe sobre as contas apresentadas pelos Chefes do executivo que deverão ficar disponíveis por sua elaboração, para a consulta e apreciação de toda a sociedade, o que era ético passa a ser obrigação legal (ANDRADE, 2008).

Ressalte-se, todavia que a LRF se revela como um mecanismo legalizado que busca o fortalecimento da cidadania, servindo de requisito ao controle social que pode ser entendido como a participação do cidadão na gestão pública, na fiscalização, no monitoramento e no controle das ações da administração Pública (CGU, 2010).

O controle social é um complemento indispensável ao controle institucional realizado pelos órgãos que fiscalizam os recursos públicos. Essa participação é importante porque contribui para a boa e correta aplicação dos recursos públicos, fazendo com que as necessidades da sociedade sejam atendidas de forma eficiente (CGU, 2010).

No entanto, para que os cidadãos possam desempenhar de maneira eficaz o controle social, é necessária a compreensibilidade das informações, já que a mera divulgação sem tornar o conteúdo compreensível para a sociedade não é transparência.

As ideias de participação e controle social estão intimamente relacionadas por meio de participação na gestão pública, os cidadãos podem intervir na tomada da decisão administrativa, orientando a administração para que adote medidas que realmente atendam ao interesse público e, ao mesmo tempo, podem exercer controle sobre a ação do Estado, exigindo que o gestor público preste conta de sua atuação (CGU, 2010).

Através das informações até então pesquisadas é fato que para haver controle social é necessário transparência, e para haver transparência pública é necessário a ampliação da divulgação das ações governamentais para todos os brasileiros.

Dessa forma, acesso às informações sob a guarda de órgãos e entidades públicas é direito fundamental do cidadão, e dever da Gestão Pública, que trata esta publicação. Direito inscrito na Constituição Federal brasileira e agora regulamentado pela Lei Federal $\mathrm{n}^{\circ}$ 12.527/2011, sancionada em 18 de novembro de 2011 pela Presidenta da República e que 
passou a vigorar somente em 16/05/2012. A referida lei trata da aplicabilidade de diretrizes para assegurar o direito de Acesso à Informação, explica os principais conceitos abordados na norma e dispõe sobre os procedimentos a serem observados pela União, Estados, Distrito Federal e Municípios, com o fim de garantir o acesso a informações (CGU, 2011).

Ao estabelecer este marco regulatório, o Brasil dá um importante passo em sua trajetória de transparência pública. Além de ampliar os mecanismos de obtenção de informações e documentos (já previstos em diferentes legislações e políticas governamentais), estabelece o princípio de que o acesso é a regra e o sigilo a exceção, cabendo à Administração Pública atender às demandas de cidadãos e cidadãs (CGU, 2011).

Em seu art. $8^{\circ} \S 2^{\circ}$ a lei obriga que seja utilizada a Internet, além de todos os meios e instrumentos legítimos que os órgãos públicos dispuserem para divulgar os atos de transparência dos governos, inclusive, os requisitos para tal promoção, exceto os municípios com menos de dez mil habitantes, os quais ficam desobrigados a divulgação na Internet (BRASIL, 2011).

Quaisquer entidades que recebam verbas públicas, ainda que privadas e sem fins lucrativos, também se subordinam ao novo regime legal. É mais um instrumento de controle que vem completar os avanços da Lei de Responsabilidade Fiscal, que já permite o acesso do cidadão, em tempo real, a informações sobre a vida financeira do ente público (receita e despesa), também via internet (BRASIL, 2011).

Para não restar dúvidas qualquer interessado poderá apresentar pedido de Acesso à Informação, através de requerimento a qualquer órgão público, por qualquer meio legitimo (email, fax, carta) basta se identificar e especificar a informação requerida, sem necessidade de alegar os motivos da solicitação (BRASIL, 2011).

$\mathrm{O}$ art. 11 da referida lei é claro, o órgão ou entidade pública deverá autorizar ou conceder o acesso imediato à informação disponível. Se não estiver disponível terá 20 (vinte) dias para comunicar a data, local e o modo para realizar a consulta; indicar as razões de fato ou de direito da recusa, total ou parcial do pedido, ou comunicar não possuir a informação requerida (BRASIL, 2011).

Segundo o art. 15 no caso de indeferimento de acesso a informações ou às razões de negativa do acesso, poderá o interessado interpor recurso contra a decisão no prazo de 10 (dez) dias a contar da sua ciência. No caso de se manter a negativa caberá recurso junto à Controladoria Geral da União - CGU, que tem o mesmo prazo para se manifestar (5 dias), 
caso a CGU mantenha a negativa, o recurso será enviado À Comissão Mista de Reavaliação de Informações (BRASIL, 2011).

Esta previsto também na lei em questão, que caberá punições para o agente público que se recusar a fornecer informações, retardar o acesso ou fornecer dados incorretos, caberá lhe processo por improbidade administrativa (BRASIL, 2011).

Os principais pontos da Lei de Acesso à Informação vêm a contribuir para o incentivo à participação popular vivenciando mais um instrumento de transparência pública.

\section{METODOLOGIA}

Ribeiro, Torres e Rocha (2006, p.190) afirmam que: "método é o caminho a ser seguido a fim de que as metas sejam atingidas. Portanto, a seleção do instrumento metodológico esta diretamente relacionada ao problema a ser estudado".

Quanto à abordagem do problema utilizou-se da pesquisa qualitativa e quantitativa. Por meio do modelo qualitativo procurou descrever a realidade encontrada, possibilitando uma análise em maior profundidade. De acordo com Longaray et al (2003, p.19) " A abordagem qualitativa visa destacar características não observadas por meio de um estudo não quantitativo".

Já a quantitativa foi utilizada para análise e interpretação dos dados, as coletas foram através de questionários contendo quinze questões (simples e de múltipla escolha), cujo roteiro foi constituído a partir dos vários fatores identificados no referencial teórico deste trabalho.

Oliveira (2001, p.115) esclarece que:

Significa quantificar opiniões, dados, nas formas de coleta de informações, assim como também com o emprego de recursos e técnicas estatísticas desde a mais simples, como porcentagem média, moeda, mediana e desvio padrão, até as de uso mais complexo, como coeficiente de correlação, analise de regressão etc. normalmente utilizados em defesas de teses.

Quanto aos fins, em relação aos objetivos da pesquisa, a metodologia utilizada tomou como base a pesquisa descritiva, pois visa analisar a percepção dos acadêmicos do curso de Ciências Contábeis sobre licitações públicas e transparência, e interpretar os variados aspectos relativos ao fato estudado.

Quanto aos meios, para alcançar os objetivos fez-se necessário à utilização da pesquisa bibliográfica que, conforme Gil (1995, p.48) “(...) é desenvolvida a partir de material já elaborado, constituído principalmente de livros científicos", é contato direto com as bibliografias escritas sobre o assunto, como: artigos, livros, dissertações e textos bem como a 
legislação vigente. Além dos referenciais teóricos,buscou-se subsídios para compreensão e discussão através das leis pertinentes ao tema.

A pesquisa telematizada apoia-se no conteúdo disponível via internet, que Vergara (1997, p.46) a conceitua como “(...) busca de informações em meios que combinam o uso do computador e de telecomunicações", foram pesquisados "sites" oficiais do Governo Federal.

Segundo Pereira (2007) o levantamento é utilizado quando envolve a interrogação direta das pessoas, cujo comportamento se deseje conhecer.

O levantamento de dados foi realizado via contato pessoal com os acadêmicos presentes em sala de aula, informando a todos sobre o objetivo da pesquisa. A coleta de dados do oitavo semestre aconteceu entre o dia 15/08/2012 ao dia 16/08/2012, com 42 alunos. Esta população se justifica pelo fato que, neste período havia aula de Trabalho de Conclusão de Curso (TTC II) o que elimina os acadêmicos que estão adiantando disciplinas. Já para o primeiro semestre aconteceu no dia 31/08/2012 com 45 acadêmicos presentes em sala de aula, totalizando 87 alunos. Os resultados obtidos foram demonstrados mediante aplicação de cálculos percentuais, com elaboração de tabelas comparativas possibilitando apresentar e discutir as percepções dos acadêmicos.

\section{RESULTADOS}

Esta seção tem por finalidade a apresentação e análise dos resultados obtidos na pesquisa. Os resultados foram apresentados por tabelas e discutidos através da comparação dos resultados percentuais dos acadêmicos iniciantes e concluintes.

Primeiramente, buscou-se saber dos acadêmicos qual o seu conceito sobre licitações públicas.

Como pode se observar na tabela 1, aproximadamente $88 \%$ dos concluintes tem conceito positivo entre bom, razoável e excelente a respeito de licitação pública. Tal dado foi influenciado pelo fato destes já terem cursado Contabilidade Pública I e II cujo conteúdo aborda conceitos diretamente ligados a Administração Pública. Conceitos como orçamentos públicos e receitas públicas, enfim várias informações para o controle social sobre as riquezas dos gastos públicos e das fontes que os financiam. Tais dados apontam para a importância da Universidade na formação desses futuros profissionais.

Enquanto, os iniciantes encontram-se com percentual de $60 \%$ entre pouco e nenhum, todavia, nas disciplinas do primeiro semestre até então não há referência sobre o tema em sua ementa. 
Estudo empírico da percepção dos acadêmicos do curso de ciências contábeis quanto às licitações públicas e transparência

Sandra Maria de Faria; Magno Alves Ribeiro; Eder Eugenio Munhão

Tabela 1. Qual seu conceito sobre Licitações Públicas.

\begin{tabular}{|c|c|c|c|}
\hline Respostas & Iniciantes \% & Concluintes \% & Total Geral \% \\
\hline Excelente & $0 \%$ & $12 \%$ & $6 \%$ \\
\hline Bom & $22 \%$ & $43 \%$ & $30 \%$ \\
\hline Razoável & $18 \%$ & $33 \%$ & $28 \%$ \\
\hline Pouco & $24 \%$ & $12 \%$ & $18 \%$ \\
\hline Nenhum & $36 \%$ & $0 \%$ & $18 \%$ \\
\hline Total & $100 \%$ & $100 \%$ & $100 \%$ \\
\hline
\end{tabular}

Fonte: Dados da Pesquisa

Na tabela 2 verificou-se novamente maior conhecimento dos concluintes sobre esta informação, das respostas positivas, $45 \%$ já ouviram falar, $21 \%$ conhecem totalmente, e $12 \%$ conhecem superficialmente. Ao analisar o percentual dos iniciantes, 56\% não tem conhecimento nenhum, quanto ao concluinte este índice diminuiu para $22 \%$. Ressalta-se que o acadêmico concluinte em sua maioria encontra-se inserido no mercado de trabalho, e nas disciplinas já cursadas pode ter aprendido que é possível participarde diversos tipos de licitações. Sendo estefato de suma importância para que se inicie o processo de fiscalização da gestão pública por parte da população.

Tabela 2. Respostas à questão: Você tem conhecimento de que pode acompanhar processos licitatórios?

\begin{tabular}{l|c|c|c}
\hline \multicolumn{1}{c|}{ Respostas } & Iniciantes \% & Concluintes \% & Total Geral \% \\
\hline Não tem conhecimento nenhum & $56 \%$ & $22 \%$ & $39 \%$ \\
Já ouviu falar & $24 \%$ & $45 \%$ & $34 \%$ \\
Conhece superficialmente & $18 \%$ & $21 \%$ & $20 \%$ \\
Conhece totalmente & $2 \%$ & $12 \%$ & $7 \%$ \\
\hline \multicolumn{1}{c|}{ Total } & $\mathbf{1 0 0 \%}$ & $\mathbf{1 0 0 \%}$ & $\mathbf{1 0 0 \%}$ \\
\hline
\end{tabular}

Fonte: Dados da Pesquisa

Em relação à questão da tabela 3, identificou-se em ambos os casos que $69 \%$ das respostas não sabemonde obter dados relacionados a licitações públicas. É preocupante, pois, os mesmos tem conhecimento que podem acompanhar licitações, mas não tem noção de onde obter essas informações. Visto que a publicidade dos atos públicos não está sendo efetiva junto a este público. Sendo estes uma parte da sociedade que cursam ensino superior e tem conhecimento suficiente para realizar uma fiscalização mais efetiva junto a Administração Pública.

Para efeitos de comparação, segundo Monteiro et al (2004) entre acadêmicos dos cursos de administração, contabilidade, economia e direito da Universidade Federal da Bahia o percentual de pessoas que não conheciam as leis de orçamento representavam $17 \%$ dos entrevistados, indicando assim que quanto maior o nível de escolaridade, maior o entendimento sobre as leis orçamentárias que também visamcontrole, fiscalização e transparência pública.

Tabela 3. Respostas à questão: Você sabe onde obter dados sobre licitações? 
Estudo empírico da percepção dos acadêmicos do curso de ciências contábeis quanto às licitações públicas e transparência

Sandra Maria de Faria; Magno Alves Ribeiro; Eder Eugenio Munhão

\begin{tabular}{lc|c|c|c}
\hline \multicolumn{1}{c|}{ Respostas } & Iniciantes \% & Concluintes \% & Total Geral \% \\
\hline Sim & $20 \%$ & $43 \%$ & $31 \%$ \\
Não & $80 \%$ & $57 \%$ & $69 \%$ \\
\hline \multicolumn{2}{r|}{} & $\mathbf{1 0 0 \%}$ & $\mathbf{1 0 0 \%}$ & $\mathbf{1 0 0 \%}$ \\
\hline
\end{tabular}

Fonte: Dados da Pesquisa

Saber qual o interesse dos acadêmicos do Curso de Ciências Contábeis é o problema desta pesquisa, como visto na tabela 4, o nível de interesse dos acadêmicos é mínimo. $\mathrm{O}$ percentual de desinteresse apresentado pelos acadêmicos iniciantes chega a 69\% e concluintes $62 \%$.Esta amostra se relaciona com o pouco conhecimento de ondeobter informações relativas a processos licitatórios.

Dados alarmantes, que caracterizam desestímulo ao interesse em acompanhar tais informações, principalmente pelos concluintes.Tais alunos estão se formando devendo ter maior preocupação com o destino do dinheiro público, sendoconscientes, participativo e exigente. Para Coelho (2009), a formação do profissional de contabilidade requer requisitos e habilidades pertinentes, a fim de que se tenham profissionais capacitados e aptos a exercer sua profissão.

Tabela 4. Respostas à questão: Você já teve interesse em acompanhar algum processo licitatório?

\begin{tabular}{|c|c|c|c|}
\hline Respostas & Iniciantes \% & Concluintes \% & Total Geral \% \\
\hline Nunca & $69 \%$ & $62 \%$ & $65 \%$ \\
\hline Uma Vez & $9 \%$ & $19 \%$ & $14 \%$ \\
\hline Algumas vezes & $20 \%$ & $19 \%$ & $20 \%$ \\
\hline Não respondeu & $2 \%$ & $0 \%$ & $1 \%$ \\
\hline Total & $100 \%$ & $100 \%$ & $100 \%$ \\
\hline
\end{tabular}

Fonte: Dados da Pesquisa

Sobre a ótica dos pesquisados, nota-se na tabela 5 uma pequena parcela dos iniciantes e concluintes quanto à participação em alguma licitação pública. Este dado se relaciona com a falta de interesse em acompanhar processos licitatórios.

Pesquisa realizada por Marques (2011)para saber o percentual de participação da sociedade tangaraense em audiências públicas identificou-se que $63 \%$ da população pesquisada nunca participaram de nenhuma audiência, e a pesquisa também revelou que $52 \%$ da população entrevistada, o maior motivo é a falta de interesse da própria população em participar do controle e fiscalização das ações governamentais.

Silva (2001), diz que participar significa influir diretamente nas decisões e controlar a execução das mesmas.

Tabela 5. Respostas à questão: Você já participou de uma licitação pública?

\begin{tabular}{l|c|c|c}
\hline \multicolumn{1}{c|}{ Respostas } & Iniciantes \% & Concluintes \% & Total Geral \% \\
\hline Nunca Participou & $96 \%$ & $79 \%$ & $87 \%$ \\
Participou uma vez & $2 \%$ & $12 \%$ & $7 \%$
\end{tabular}


Estudo empírico da percepção dos acadêmicos do curso de ciências contábeis quanto às licitações públicas e transparência

Sandra Maria de Faria; Magno Alves Ribeiro; Eder Eugenio Munhão

\begin{tabular}{|c|c|c|c|}
\hline Participou algumas vezes & $2 \%$ & $7 \%$ & $5 \%$ \\
\hline Participa sempre & $0 \%$ & $2 \%$ & $1 \%$ \\
\hline Não respondeu & $0 \%$ & $0 \%$ & $0 \%$ \\
\hline Total & $100 \%$ & $100 \%$ & $100 \%$ \\
\hline
\end{tabular}

Fonte: Dados da Pesquisa

Observa-se na tabela 6 que pouco mais de $61 \%$ dos iniciantes e concluintes raramente ou nunca acompanha notícias relacionadas ao tema.Esse resultado corrobora com a pesquisa de Monteiro et al (2004),pois 62\% dos entrevistados responderam nunca ter acompanhado notícias ou acessado internet com intuito de fiscalizar as contas públicas.

Como já visto nas tabelas 3, 4 e 5 muitos acadêmicos afirmam não ter interesse em acompanhar licitações públicas, nãoparticipou de nenhum processo licitatório e não sabem onde obter dados relacionados.

É importante incentivar o acadêmico a participar de audiências públicas, acompanhar notícias, acessar sites que informam sobre licitações e transparência pública. A Universidade pode promover palestras de conscientização e incentivo.Segundo Silva e Alfradique (2010), a informação e o conhecimento atualizados são de grande importância, gera maior capacidade de vigiar e fiscalizar.

Tabela 6. Respostas à questão: Você acompanha notícias relacionadas às licitações públicas?

\begin{tabular}{|c|c|c|c|}
\hline Respostas & Iniciantes \% & Concluintes \% & Total Geral \% \\
\hline Nunca & $38 \%$ & $43 \%$ & $40 \%$ \\
\hline Raramente & $18 \%$ & $24 \%$ & $21 \%$ \\
\hline Às vezes & $33 \%$ & $21 \%$ & $28 \%$ \\
\hline Frequentemente & $7 \%$ & $12 \%$ & $9 \%$ \\
\hline Sempre & $4 \%$ & $0 \%$ & $2 \%$ \\
\hline Total & $100 \%$ & $100 \%$ & $100 \%$ \\
\hline
\end{tabular}

Fonte: Dados da Pesquisa

Verificou-se na Tabela 7 que apesar de $95 \%$ das respostas negativas crer que possa ocorrer alguma fraude em processo licitatório, poucos, de fato, admitem acompanhar notícias relacionadas ao assunto. Tanto iniciantes quanto concluintes, acreditam que possa ocorrer fraude durante a realização de uma licitação pública. Esta máxima a cerca do assunto devemse as noticiais sobre escândalos públicos e corrupções veiculadas na mídia, principalmente nos anos de 2010 a 2012.

Tabela 7. Respostas à questão: Você acredita que possa ocorrer fraude em licitações públicas?

\begin{tabular}{|c|c|c|c|}
\hline Respostas & Iniciantes \% & Concluintes \% & Total Geral \% \\
\hline Nunca & $4 \%$ & $0 \%$ & $2 \%$ \\
\hline Raramente & $7 \%$ & $0 \%$ & $3 \%$ \\
\hline Às vezes & $29 \%$ & $26 \%$ & $28 \%$ \\
\hline Frequentemente & $33 \%$ & $43 \%$ & $38 \%$ \\
\hline Sempre & $27 \%$ & $31 \%$ & $29 \%$ \\
\hline Total & $100 \%$ & $100 \%$ & $100 \%$ \\
\hline
\end{tabular}

Fonte: Dados da Pesquisa 
Estudo empírico da percepção dos acadêmicos do curso de ciências contábeis quanto às licitações públicas e transparência

Sandra Maria de Faria; Magno Alves Ribeiro; Eder Eugenio Munhão

A obrigação de divulgação está nos moldes previstos na lei 8.666/93 e vinculados ao Princípio da Publicidade o qual é atribuído ao gestor público de dar total transparência e informações solicitadas de todos os atos públicos, nesse sentido a Tabela 8 apresenta o percentual de considerações sobre informações de licitações públicas.

As informações sobre licitações públicas são tidas como importante e muito importante por aproximadamente $84 \%$ da totalidade das duasrespostas. Ressalta-se que $61 \%$ afirmam não acompanhar notícias e $65 \%$ não apresenta interesse sobre tais informações.

Os casos relacionados à licitação pública, divulgados pela mídia são importantes, pois servem como crítica ou até para investigação do governo, servindo de insumo para a sociedade, para ficar atenta ao uso de funções públicas (SPECK, 2002).

Tabela 8. Respostas à questão: Você considera a divulgação de informações sobre licitações públicas:

\begin{tabular}{|c|c|c|c|}
\hline Respostas & Iniciantes \% & Concluintes \% & Total Geral \% \\
\hline Irrelevante & $13 \%$ & $5 \%$ & $9 \%$ \\
\hline Pouco importante & $7 \%$ & $5 \%$ & $6 \%$ \\
\hline Importante & $34 \%$ & $36 \%$ & $34 \%$ \\
\hline Muito Importante & $44 \%$ & $54 \%$ & $50 \%$ \\
\hline Sem Importância & $2 \%$ & $0 \%$ & $1 \%$ \\
\hline Total & $100 \%$ & $100 \%$ & $100 \%$ \\
\hline
\end{tabular}

Fonte: Dados da Pesquisa

Foi constatada na tabela 9 uma diversidade de percepções entre raramente e às vezes os princípios administrativos são seguidos durante a condução do processo licitatório. Essa informação relaciona-se com o fato de grande parte dos acadêmicos terem conhecimento de alguma fraude ocorrida em licitação e também por poucos terem participado de algum processo licitatório conforme demonstrado nas tabelas 5 e 7 .

Como rege a LRF é importante o controle social visando verificar os princípios constitucionais como os citados no Quadro 1. Silva e Alfradique (2010) alertam para a importância do controle social visando verificar os princípios constitucionais, dessa forma, pode-se efetuar a fiscalização contábil, financeira, orçamentária patrimonial e operação dos órgãos públicos.

Tabela 9. Respostas à questão: Você acredita que princípios administrativos são seguidos durante a realização as licitações?

\begin{tabular}{|c|c|c|c|}
\hline Respostas & Iniciantes \% & Concluintes \% & Total Geral \% \\
\hline Nunca & $13 \%$ & $5 \%$ & $9 \%$ \\
\hline Raramente & $22 \%$ & $29 \%$ & $26 \%$ \\
\hline Às vezes & $45 \%$ & $52 \%$ & $48 \%$ \\
\hline Frequentemente & $16 \%$ & $12 \%$ & $14 \%$ \\
\hline Sempre & $4 \%$ & $2 \%$ & $3 \%$ \\
\hline Total & $100 \%$ & $100 \%$ & $100 \%$ \\
\hline
\end{tabular}

Fonte: Dados da Pesquisa 
Estudo empírico da percepção dos acadêmicos do curso de ciências contábeis quanto às licitações públicas e transparência

Sandra Maria de Faria; Magno Alves Ribeiro; Eder Eugenio Munhão

As informações referentes a processos licitatórios são tidas como raramente e às vezes confiáveis por $79 \%$ dos alunos iniciantes, entre os concluintes esse percentual aumenta para 81\%. Tal informação denota desconfiança dos acadêmicos em relação aos dados divulgados pelo poder público.Isto se deve pelo fato de terem conhecimento de algum tipo de fraude ocorrida durante alguma licitação, e poucos acreditam que os princípios constitucionais estão sendo seguidos nos processos licitatórios como visto na tabela 9.

Como já citado no texto, na legislação há normas, diretrizes e princípios tanto licitatórios como administrativos que asseguram as diversas formas a contratação de licitações.Porém, na prática às vezes ocorrem algumas formas de lesão às riquezas públicas, impedindo que a proposta mais vantajosa seja realmente a vencedora da licitação.

Por isso é importante acompanhar a gestão pública, cobrando soluções de problemas, exigir melhores resultados e principalmente participar da formalização das políticas públicas para se tomar medidas preventivas.

Tabela 10. Respostas à questão: As informações divulgadas sobre processos licitatórios são confiáveis?

\begin{tabular}{|c|c|c|c|}
\hline Respostas & Iniciantes \% & Concluintes \% & Total Geral \% \\
\hline Nunca & $13 \%$ & $7 \%$ & $10 \%$ \\
\hline Raramente & $29 \%$ & $60 \%$ & $44 \%$ \\
\hline Às vezes & $50 \%$ & $21 \%$ & $36 \%$ \\
\hline Frequentemente & $4 \%$ & $7 \%$ & $5 \%$ \\
\hline Sempre & $4 \%$ & $5 \%$ & $5 \%$ \\
\hline Total & $100 \%$ & $100 \%$ & $100 \%$ \\
\hline
\end{tabular}

Fonte: Dados da Pesquisa

Os resultados apontados na tabela 11 demonstra-se que entre os iniciantes e concluintes, teve-se como maior percentual de respostas à opção bom e razoável. Entre as respostas positivas nota-se que $65 \%$ dos acadêmicos sabem alguma informação acerca de transparência pública. Observa-se também que $24 \%$ dos iniciantes não tem nenhum conhecimento sobre a questão, já o oitavo semestre todos tem conceito positivo.

Speck (2002) afirma que ao se desenvolverem sistemas preventivos, buscando trazer maior transparência a prestação de contas podem diminuir as oportunidades para que sejam feitos acordos de maneira corrupta, afrontando o interesse público.

Tabela 11. Qual seu conhecimento sobre Transparência Pública:

\begin{tabular}{lc|c|c|c}
\hline \multicolumn{1}{c}{ Respostas } & Iniciantes \% & Concluintes \% & Total Geral \% \\
\hline Excelente & $7 \%$ & $10 \%$ & $8 \%$ \\
Bom & $19 \%$ & $26 \%$ & $18 \%$ \\
Razoável & & $30 \%$ & $57 \%$ & $47 \%$ \\
Pouco & $20 \%$ & $7 \%$ & $14 \%$ \\
Nenhum & & $24 \%$ & $0 \%$ & $13 \%$ \\
\hline \multicolumn{2}{c|}{} & $\mathbf{1 0 0 \%}$ & $\mathbf{1 0 0 \%}$ & $\mathbf{1 0 0 \%}$ \\
\hline
\end{tabular}

Fonte: Dados da Pesquisa 
Estudo empírico da percepção dos acadêmicos do curso de ciências contábeis quanto às licitações públicas e transparência

Sandra Maria de Faria; Magno Alves Ribeiro; Eder Eugenio Munhão

Já na tabela 12 os iniciantes encontram-se com uma grande parcela de respostas entre frequentemente e sempre, equivale a $60 \%$ das duas respostas. Para os concluintes o percentual aumentou para62\%. Mesmo com pouca percepção acerca de transparência pública, os dados demonstram a importância dada pelos acadêmicos quanto àdivulgação de informações relacionadas às licitações.

Conforme CGU (2011), a sociedade deve efetuar um controle mais efetivo sobre a gestão pública, é necessário que ela, além de se conscientizar deve-se nutrir interesse pelo bem comum da coletividade. Assim estão à disposição da sociedade diversos instrumentos de controle e fiscalização entre eles a nova lei de Acesso a Informação $n^{\circ}$ 12.527/2011 a qual veio a contribuir para com a LRF onde há instituídos instrumentos de transparência e controle.

Tabela 12. Respostas à questão: A falta de transparência nos processos licitatórios pode incentivar condutas antiéticas no serviço público?

\begin{tabular}{|c|c|c|c|}
\hline Respostas & Iniciantes \% & Concluintes \% & Total Geral \% \\
\hline Nunca & $4 \%$ & $0 \%$ & $2 \%$ \\
\hline Raramente & $7 \%$ & $5 \%$ & $6 \%$ \\
\hline Às vezes & $24 \%$ & $33 \%$ & $29 \%$ \\
\hline Frequentemente & $29 \%$ & $12 \%$ & $20 \%$ \\
\hline Sempre & $36 \%$ & $50 \%$ & $43 \%$ \\
\hline Total & $100 \%$ & $100 \%$ & $100 \%$ \\
\hline
\end{tabular}

Fonte: Dados da Pesquisa

Os resultados demonstrados na tabela 13, ambos os casos, entre frequentemente e sempre, com $68 \%$ do total das respostas acredita que, caso nãoexista transparência, o controle social dos processos licitatórios é prejudicado. Apesar de pouco interesse em acompanhar licitações públicas, os acadêmicos julgam importante à divulgação de informações relacionadas às mesmas conforme demostrado nastabelas 4 e 8 .

Monteiro et al (2004) ressalta na conclusão de sua pesquisa que a transparência buscada pela Lei visa permitir um controle social mais efetivo, partindo do pressuposto de que, conhecendo a situação das contas públicas, o cidadão terá muito mais condições de cobrar, exigir e fiscalizar, com isso, a própria LRF estabelece alguns instrumentos importantes para incrementar o controle social.

Tabela 13. Respostas à questão: A falta de transparência prejudica o controle social?

\begin{tabular}{|c|c|c|c|}
\hline Respostas & Iniciantes \% & Concluintes \% & Total Geral \% \\
\hline Nunca & $7 \%$ & $0 \%$ & $3 \%$ \\
\hline Raramente & $7 \%$ & $2 \%$ & $5 \%$ \\
\hline Às vezes & $20 \%$ & $29 \%$ & $24 \%$ \\
\hline Frequentemente & $31 \%$ & $24 \%$ & $28 \%$ \\
\hline Sempre & $35 \%$ & $45 \%$ & $40 \%$ \\
\hline Total & $100 \%$ & $100 \%$ & $100 \%$ \\
\hline
\end{tabular}

Fonte: Dados da Pesquisa 
A pesquisa buscou identificar o conceito dos acadêmicos sobre a Lei 12.527/2011, os resultados da tabela 14 demonstra um percentual de $84 \%$, o qual reflete-se que os acadêmicos iniciantes não tem conhecimento nenhum sobre a lei. Entre os concluintes esse percentual diminuiu para $69 \%$, mesmo assim nenhum acadêmico conhece totalmente.

A lei $12.527 / 11$ é um instrumento novo de acesso à informação e poucos têm conhecimento sobre a mesma. Conforme as normas regidas na supracitada lei os caminhos abrem-se para a sociedade adentrar aos órgãos públicos federais, estaduais e municipais (ministérios, estatais, governos estaduais, prefeituras, autarquias etc.). conforme suas normas e regras a supracitada lei obriga os órgãos públicos a oferecer informações relacionadas às suas atividades a qualquer pessoa que solicitar. Vale lembrar que toda a lei que estimule a prestação de contas deve-se dar especial atenção ao modo de publicação das informações, como forma de facilitar o acesso e a coleta dos dados, a lei faz-se valer nossos direitos e as obrigações dos gestores públicos.

Para o conhecimento geral, a Escola Virtual da CGU disponibiliza cursos, vídeos e publicações voltadas para cidadãos, com o objetivo de promover o controle social e orientar a população sobre os gastos públicos, tais cursos são totalmente gratuitos.

Entre os cursos existentes, a CGU disponibiliza o curso "rumo a uma cultura de acesso à informação: a Lei 12.527/2011”, o objetivo do referido curso é apresentar uma visão geral sobre a lei de Acesso a Informação, abordando o marco teórico conceitual e a cultura de transparência e acesso à informação pública.

Para participar dos cursos basta ter acesso à internet, inscrever-se através do site da CGU, possuir um endereço de e-mail e conhecimento básicos de informática como acesso a sites e uso de e-mails.

Tabela 14: Qual seu conhecimento sobre a Lei 12.527/11?

\begin{tabular}{l|c|c|c}
\hline \multicolumn{1}{c|}{ Respostas } & Iniciantes \% & Concluintes \% & Total Geral \% \\
\hline Não tem conhecimento nenhum & $84 \%$ & $69 \%$ & $78 \%$ \\
Já ouviu falar & $7 \%$ & $14 \%$ & $10 \%$ \\
Conhece superficialmente & $9 \%$ & $17 \%$ & $12 \%$ \\
Conhece totalmente & $0 \%$ & $0 \%$ & $0 \%$ \\
\hline \multicolumn{1}{c|}{ Total } & $\mathbf{1 0 0 \%}$ & $\mathbf{1 0 0 \%}$ & $\mathbf{1 0 0 \%}$ \\
\hline
\end{tabular}

Fonte: Dados da Pesquisa

Na tabela 15 identificou que entre os acadêmicos iniciantes $56 \%$ consideram ruim e péssimo a transparência pública entre os últimos três anos, este percentual aumenta para 74\% entre os concluintes. Já na pesquisa de Marques (2011), sobre transparência na gestão pública 
Estudo empírico da percepção dos acadêmicos do curso de ciências contábeis quanto às licitações públicas

e transparência

Sandra Maria de Faria; Magno Alves Ribeiro; Eder Eugenio Munhão

municipal de Tangará da serra nos últimos 3 anos, 55\% da população pesquisada responderam que o processo de transparência na gestão municipal é péssimo.

Ressalta-se que muitos acadêmicos afirmaram que a falta de transparência incentiva à ocorrência de condutas antiéticas no serviço público, acredita que a falta de transparência prejudica o controle social feito sobre os processos licitatórios e a maioria não tem conhecimento sobre a lei de Acesso a Informação, conforme tabelas 12, 13 e 14.

Segundo Souza et al (2009) a caracterização da transparência se dá através da participação do cidadão nas decisões que resultam em gastos de recursos obtidos da sociedade.

Tabela 15: Como você avalia a transparência pública nos últimos três anos?

\begin{tabular}{|c|c|c|c|}
\hline Respostas & Iniciantes \% & Concluintes \% & Total Geral \% \\
\hline Ótimo & $0 \%$ & $0 \%$ & $0 \%$ \\
\hline Indiferente & $27 \%$ & $12 \%$ & $20 \%$ \\
\hline Bom & $17 \%$ & $14 \%$ & $16 \%$ \\
\hline Ruim & $36 \%$ & $53 \%$ & $44 \%$ \\
\hline Péssimo & $20 \%$ & $21 \%$ & $20 \%$ \\
\hline Total & $100 \%$ & $100 \%$ & $100 \%$ \\
\hline
\end{tabular}

Fonte: Dados da Pesquisa

Conforme já comentado anteriormente, a LRF determina vários dispositivos de informações em tempo real por meios eletrônicos, seguindo esta mesma linha há vários instrumentos de transparência como:

Quadro 2. Portais de transparência pública

\begin{tabular}{|l|l|}
\hline Portal da Transparência & $\begin{array}{l}\text { Funciona como um instrumento de prestação de contas da Administração Pública, lá } \\
\text { encontra-se dados detalhados sobre execução orçamentária e financeira do governo } \\
\text { federal, e recursos públicos transferidos pela União aos estados e municípios } \\
\text { brasileiros. }\end{array}$ \\
\hline TCU & $\begin{array}{l}\text { Tribunal de Contas da União é um portal a serviço da sociedade, ele é responsável por } \\
\text { exercer a fiscalização contábil, financeira e orçamentaria da União e das entidades da } \\
\text { Administração direta e indireta; }\end{array}$ \\
\hline CGU & $\begin{array}{l}\text { Controladoria Geral da União é responsável por fiscalizar e detectar fraudes em relação } \\
\text { ao uso do dinheiro público federal, além do mais o portal é responsável por } \\
\text { desenvolver mecanismos de prevenção à corrupção, seu objetivo é não apenas detectar } \\
\text { casos de corrupção e sim desenvolver mecanismos de prevenção à corrupção. }\end{array}$ \\
\hline $\begin{array}{l}\text { Portal de Acesso a } \\
\text { Informação Pública }\end{array}$ & $\begin{array}{l}\text { Este portalfoi desenvolvido com objetivo de ser uma ferramenta útil para a sociedade, } \\
\text { através dele o cidadão pode captar informações e verificar se o administrador público } \\
\text { cumpre com os princípios constitucionais e do direito administrativo, respeitando os } \\
\text { contratos, as licitações e demais serviços. }\end{array}$ \\
\hline
\end{tabular}

Fonte: Dados obtidos pelos sites oficiais do Governo Federal, elaborado pelos autores. 


\section{CONCLUSÃO}

Destacou-se no desenvolver da pesquisa que a transparência está caminhando para um passo histórico no Brasil. Com ela, todos os brasileiros poderão consultar documentos e informações a respeito dos gastos públicos produzidos pela administração pública.

A análise geral dos resultados obtidos na pesquisa induziu a resposta do problema proposto. Diante das amostras os acadêmicos não participam ativamente do processo de fiscalização dos atos públicos e não apresentam interesse por certames licitatórios realizados pela administração pública. Tais fatos se comprovam, pois65\% dos acadêmicos nunca tiveram interesse em acompanhar algum processo licitatório. É necessário buscar formas de fazer com que o acadêmico tenha participação contínua na gestão pública, gerando consequentemente maior senso crítico a respeito. Não basta apenas cobrar dos gestores, mas sim participar ativamente do processo de fiscalização.

Interpreta-se através da leitura das tabelas uma expressiva parcela da totalidade dos iniciantes/concluintes não sabem onde encontrar dados sobre licitações,nunca participou, e não acompanha notícias relacionadas ao tema e não confia nas informações divulgadas sobre licitações. Porém, acredita ser importante a divulgação de informações sobre licitações, que a falta de transparência incentiva à ocorrência de condutas antiéticas no serviço público e afirma que a falta de transparência prejudica o controle social feito sobre os processos licitatórios.

Vale ressaltar que o objetivo desta pesquisa foi alcançado, visto que a percepção dos acadêmicos foi modificando em relação ao inicio do curso, os concluintes possuem maior conceito acerca de licitações públicas, e conhecimento de que pode acompanhar informações a respeito. Quanto à transparência é necessária a realização constante de pesquisas para melhor entender os meios a ser percorridos, pois, as páginas de Transparência Pública integram uma lista de ações de governo voltadas para o controle social.

Em relação aos objetivos específicos o primeiro foi alcançado, pois foi feito uma abordagem sobre as normas e regras, definidos pela lei $\mathrm{n}^{\circ}$ 8.666/93 "Lei de Licitações e Contratos Administrativos" e a nova Lei de Acesso a Informação $n^{\circ} 12.527 / 11$ que trata de Transparência, Controle e Fiscalização, o segundo objetivo também foi alcançado, constatouse que a Universidade agrega conhecimento ao acadêmico, conforme a tabela 1 e 2, comparando as afirmativas do iniciante e o concluinte as percepções fez referencia ao conceito modificando-o para melhor a respeito do tema. 
Sugerem-seoutras pesquisasque reavaliem os fatores identificados nos resultados, como por exemplo, porque há falta de interesse dos acadêmicos em acompanhar e/ou participar de processos licitatórios, de forma a comparar os resultados obtidos em momentos distintos. Em menor ou maior percentual, direta ou indiretamente, toda pessoa precisa exercitar a cidadania, para coibir descasos praticados pelo poder público.

\section{REFERÊNCIAS}

ANDRADE, Nilton de Aquino. Contabilidade pública na gestão municipal. 1 ed. São Paulo: Atlas, 2002, cap.2.

ANDRADE, Rogério Vieira. O Planejamento e a transparência na gestão fiscal. 2008 Disponível em: <http://www.webartigos.com,/artigos/o-planejamento-e-a-transparencia-nagestao-fiscal/3499/>. Acesso em 27 de Julho de 2012.

BRASIL. Constituição Federal. 7. ed. Rev., atual. E ampl. São Paulo: Revista dos Tribunais, 2002.

BRASIL. Decreto 3.555 de 08 de agosto de 2000. Aprova o Regulamento para a modalidade de licitação denominada pregão, para aquisição de bens e serviços comuns.

BRASIL. Lei 10.520/2002 de 17 de junho de 2002. Instituem no âmbito da União, Estados, Distrito Federal e Municípios, nos termos do art. 37, inciso XXI, da Constituição Federal, modalidade de licitação denominada pregão, para aquisição de bens e serviços comuns, e da outras providências. Brasília, DF, 2002.

BRASIL. Lei 12.527 de 18 de Novembro de 2011, e 2000. Regula o acesso a informações previsto no inciso XXXIII do art. $5^{\circ}$, no inciso II do $\S 3^{\circ}$ do art. 37 e no $\S 2^{\circ}$ do art. 216 , da Constituição Federal. Disponível em: <http://www.planalto.gov.br/ccivil_03/_ato20112012/2011/lei/112527.htm>. Acesso em 06 de Agosto 2012.

BRASIL. Lei Complementar $\mathbf{n}^{\mathbf{0}}$ 101, de 4 de Maio de 2000.Estabelece normas de finanças públicas voltadas para a responsabilidade na gestão fiscal e dá outras providencias. Disponível em: <http://www.planalto.gov.br/ccivil_03/leis/lcp/lcp101.htm>. Acesso em 09 abr. 2012.

BRASIL. Lei no 8.666/1993, de 210 de junho de 1993. Regulamentada o art. 37, inciso XXI da Constituição Federal, institui normas para licitações e contratos da Administração Pública e dá outras providencias. Brasília, DF, 1993.

CGU, Controladoria Geral da União. A participação popular no Estado brasileiro In: Coleção olho vivo - controle social. Brasília, 2010. $2^{\circ}$ edição Disponível em: $<$ http://www.cgu.gov.br/Publicacoes/CartilhaOlhoVivo/ControleSocial.asp $>$. Acesso em 09 de Julho 2012.

CGU, Controladoria Geral da União. Acesso à Informação Pública: Uma introdução à Lei 12.527, de 18 de novembro de 2011, Disponível em: 
Estudo empírico da percepção dos acadêmicos do curso de ciências contábeis quanto às licitações públicas e transparência

Sandra Maria de Faria; Magno Alves Ribeiro; Eder Eugenio Munhão

<http://www.cgu.gov.br/publicacoes/CartilhaAcessoInformacao/index.asp $>$. Acesso em: 03 julho 2012.

CGU, Controladoria Geral da União. O Controle das Ações Governamentais In: Coleção olho vivo - controle social. Brasília, 2010. $2^{\circ}$ edição Disponível em:

<http://www.cgu.gov.br/Publicacoes/CartilhaOlhoVivo/ControleSocial.asp $>$. Acesso em 09 de Julho 2012.

CGU, Controladoria Geral da União. Operação Hygea (MT). Disponível em:

<http://www.cgu.gov.br/AreaAuditoriaFiscalização/Auditoriaespeciais/2010.asp\#9>. Acesso em 03 de Março de 2012.

COELHO, José Martonio Alves. O desenvolvimento profissional, na visão do CFC.

Revista Brasileira de Contabilidade, $\mathrm{n}^{\circ} .176$ mar/abr. p.13, 2009.

DALVI, Luciano. Manual das Licitações e Contratos Administrativos. $1^{\text {a }}$ ed. Campo Grande: Contemplar, 2012.

G1, O portal de noticiais da globo. Fantástico mostra como é feita fraude em licitações da saúde pública. Disponível em:

$<$ http://g1.globo.com/rio_de janeiro/noticia/2012/03//fantastico-mostra-e-desvio-de-dinehiroem-um-hospital-publico.html>. Acesso em 03 de Março 2012.

GIL, Antônio Carlos. Método e Técnicas de Pesquisa Social. ed. 4, São Paulo - SP: Atlas, 1995.

GOMES FILHO, Adhemar B.. O desafio de implementar uma gestão pública transparente. Disponível em:

$\langle$ http://bvc.cgu.gov.br/bitstream/123456789/1889/1/0052549.pdf $>$. Acesso em 08 de Outubro de 2012.

LONGARAY et al. Como Elaborar Trabalhos Monográficos em Contabilidade: Teoria de Prática. São Paulo: Atlas, 2003.

MARQUES, Ezequiel Batista. A transparência e o controle social na gestão pública municipal de Tangará da Serra. Tangará da Serra-MT, p.16-17, 2011.

MEIRELLES, Helly Lopes. Direito Administrativo Brasileiro. ed. $33^{\circ}$ - São Paulo - SP: Editora Medalheiros, 1990,cap. 3, p.59-83.

MENDES, Marcos. Eficiência do gasto público: o governo focado na solução das "falhas de mercado". Disponível em:

$<$ http://www.pm.rn.gov.br/contentproducao/aplicacao/searh_escola/arquivos/pdf/paper_eficie nciagastopublico_mmendes.pdf>. Acesso em 08 de Outubro de 2012.

MONTEIRO, Álvaro; LACERDA, Manoel Messias; LUZ, Reginaldo Sales. A transparência da gestão fiscal na administração pública sob ótica da sociedade. Salvador: UFB 2004. Disponível em: <http://intranet.sefaz.ba.gov.br/gestao/rh.pdf/>. Acesso em: 30 de Agosto 2012. 
OLIVEIRA, Silvio Luiz. Tratado de metodologia Cientifica: Projetos de Pesquisa, TGI, TCC, Monografia, Dissertações e Teses. $2^{\circ}$ edição. São Paulo: Pioneira Thomson Learning, 2001.

PEREIRA, José Matias. Manual de Metodologia da Pesquisa Científica. São Paulo: Atlas, 2007.

RIBEIRO, Magno Alves; TORRES, Ariel Lopes; ROCHA, Margarida Alves. Manual para elaboração e apresentação de monografias: com noções introdutórias de metodologia. Tangará da Serra, MT: UNEMAT, 2006.

SANTANA, Jair Eduardo. Pregão Presencial e Eletrônico Manual de Implantação, Operacionalização e Controle. ed. $2^{\circ}$ - São Paulo - SP: Editora Fórum, p.33, 2008.

SILVA, Gecilda. E.; ALFRADIQUE, Cláudio N. A importância da participação popular como forma de controle social de obras públicas e exercício da cidadania. Disponível em: <http://www2.tce.pr.gov.br/trabalhos/importancia\%20da\%20participaçao\%2popular.pdf >. Acesso em 01 de Setembro 2012.

SILVA, Marcelo Kunrath. Construção da "Participação Popular". Análise comparativa de processos de participação social na discussão pública do orçamento em munícipios da Região. Porto Alegre, 2001, p.381. Disponível em: $\langle\underline{w w w}$.democraciaparticipativa.org/files/marcelosilva.pdf $>$. Acesso em 30 de Agosto 2012.

SOUZA, A. C.; SANTANA, J. A> O.; CRUZ, M. P. S.; SILVA, C. E. . A relevância da transparência na gestão pública municipal. Revista Campus, Paripiranga, V.2, n.5, p.6-20, 2009.

SPECK, Bruno. W. Caminhos de transparência. Campinas: Unicamp, 2002. Disponível em: <https://bvc.cgu.gov.br/bandle/123456789/2567>. Acesso em 01 de Setembro de 2012.

TCU, Tribunal de Contas da União. Licitações e Contratos: orientações básicas. 2. ed. Brasília: TCU, Secretaria de Controle Interno, 2003. Disponível em: <http://www.tcu.gov.br/portal/gocs/20023810783/pdf/>. Acesso em 30 de Julho 2012.

TOLOSA FILHO, Benedicto de. Pregão uma nova modalidade de Licitação. ed. $2^{\mathrm{a}}$ - Rio de Janeiro - RJ: Editora Forense, p.05, 2005.

VERGARA, Sylvia Constant. Projetos e Relatórios de Pesquisa em Administração. - São Paulo - SP: Editora Atlas, 1997. 